\title{
Women Empowerment and Frequency of Meal Intake Among Children in Ghana
}

Louis Kobina Dadzie ( $\square$ louis.dadzie1@stu.ucc.edu.gh )

University of Cape Coast https://orcid.org/0000-0003-4764-7605

Joshua Amo-Adjei

University of Cape Coast

Kobina Esia-Donkoh

University of Cape Coast

Research

Keywords: frequency, infant, feeding, meal, practice, empowerment, women

Posted Date: December 10th, 2020

DOI: https://doi.org/10.21203/rs.3.rs-123025/v1

License: (1) This work is licensed under a Creative Commons Attribution 4.0 International License.

Read Full License 


\section{Abstract}

\section{Background}

Quality nutrition is an important basis of health and well-being, especially for children as their bodies need to grow, develop and reach their physical and mental potential. Women's empowerment is not only important for women's human rights, but also improves nutrition outcomes of both mothers and their children. This study sought to investigate the association between women's empowerment and minimum meal frequency in Ghana.

\section{Methods}

The study used data from the 2014 Ghana Demographic and Health Survey (GDHS). A sample of 1,640 mother-child (6-23 months) dyad was used and univariate and multiple linear regression techniques were applied.

\section{Results}

Decisions on large household purchases $(\beta=0.351, p<0.01)$ and family visits $(\beta=0.743, p<0.01)$, ownership over house $(\beta=-0.245, p<0.10)$, age of child $(\beta=1.387, p<0.01)$, mother's educational attainment $(\beta=0.496$, $p<0.10)$ and residence $(\beta=-0.298, p<0.10)$ were significantly associated with minimum meal frequency in Ghana.

\section{Conclusion}

Minimum meal frequency was largely influenced by economic and socio-familial empowerment of women as decisions on large household purchases and family visits showed association with minimum meal frequency. Interventional programs should target households and mothers with lower sociodemographics characteristics such as lower educational level.

\section{Key Messages}

1. Minimum meal frequency is influenced by various dimensions of empowerment of women such as economic and socio-familial empowerment.

2. There is the need for improved advocacy for women to be involved in decision on family visits and large household purchases as it promotes frequent meal attainment of children

3. Interventional programs should target households and mothers with lower socio-demographics characteristics such as lower educational level and those residing in rural areas to improve feeding at least the minimum frequency of children.

\section{Introduction}


Quality nutrition is an important basis of health and well-being, especially for children for physical and mental development [1]. Accordingly, The Convention on the Rights of the Child recognizes that every infant and child has the right to good nutrition [2]. This has also found expression in the SDG Goal 2 ("End hunger, achieve food security and improved nutrition and promote sustainable agriculture") and 3 ("Ensure healthy lives and promote wellbeing for all at all ages).

Infant and young child feeding (IYCF) is considered a key area to improving child survival and promoting healthy growth and development [3] [4] [5] [6]. Improved child nutrition is protective against several childhood illnesses, including gastrointestinal infections and malnutrition and fosters better development overall [7]. In pursuit of this, the WHO and the UNICEF recommend the introduction of nutritionally adequate and safe complementary (solid) foods from six months together with continued breastfeeding up to two years of age or beyond [8]. Consequently, the WHO designed the IYCF tool with the view to improve and protect, promote, and support optimal infant and young child feeding [9]. One of such indicators is the minimum meal frequency which can be defined as minimum number of meals to be consumed in a day [9] [10] [11].

Despite the immense benefits of children achieving minimum meal frequency, few children receive nutritionally adequate and safe complementary foods appropriate to their age [12]. Evidence shows that about 52 percent of all children 6-23 months of age are not receiving the minimum recommended number of meals a day with South Asia and sub-Saharan Africa having the lowest rates of minimum meal frequency of all [9]. In Ghana, only 43 percent of children within 6-23 months are fed with the minimum number of meals in a day. Many factors account for the inability of caregivers to provide adequate nutrition for children. These include poverty, food insecurity, maternal ill health and stressful mealtimes [13] [14].

Challenges associated with child feeding practices and undernutrition in Ghana results from poverty, lack of financial support from husbands or partners, cultural beliefs/ practices, workload on the part of the caregivers and interference of grandmothers [15] [16]. Some scholars (e.g. Mulenga et al., 2019 [17]) contend that underlying these issues is the lack of women's empowerment. Women and girls constantly face various forms of disempowerment in many respects: health, economic, social and politics which, to a large extent, create discriminatory tendencies and distortions in the human development pathways [18] [19]. In essence, women's empowerment is not only important for women's human rights, but also improves nutrition outcomes of both mothers and their children [20] [21].

Despite efforts of health workers to increase the number of children attaining the recommended practices, not much success has been achieved. This is because, feeding practices are often difficult to change as they are directly related to varied economic, socio-cultural and religious factors in the community and to various dynamics prevailing at the household level [22]. While the study acknowledges that there has been an increasing and impressive scholarship on IYCF in Ghana, available evidence shows that previous studies have focused largely on nutritional knowledge [23] [24], stunting [25] [26] and child dietary diversity [27] [28] with little or no link to empowerment. 
This study, therefore, sought to determine the association between women's empowerment and minimum meal frequency in Ghana. This is importance given that several development interventions have explicitly aimed at women's empowerment [29]. Some of these programmes have targeted micro credit for women as an economic empowerment valve as well as formal education [30] [31]. Empowerment theory [32] assumes that personal, interpersonal and environmental resources are needed to increase and improve the skills, knowledge and motivation of people to achieve valid roles. They propose strategies for capacity building, awareness building and skill development to improve the status of the marginalized. This theory suggests that when women are denied access to resources needed for good health, interpersonal skills and valued social roles, they are rendered powerlessness and their functioning is undermined.

\section{Methods}

\section{Source of Data and Sampling Procedure}

The study used data from the 2014 Ghana Demographic and Health Survey (GDHS). The GDHS is a cross-sectional nationwide survey designed and conducted every five years since 1988. The data is collected on fertility, antenatal care, delivery care and postnatal care, contraceptive use, child health, and family planning. The GDHS generally focuses on child and maternal health, and is designed to provide adequate data to monitor the population and health situation in Ghana. That notwithstanding, data on men are collected at each round to provide a context to understand women and children's health. The 2014 GDHS interviewed 9,396 women aged 15-49 from 12,831 households, covering 427 clusters throughout Ghana [33]. The 2014 GDHS followed a two-stage sample design. The first stage involved selecting sample points (clusters) consisting of enumeration areas (EAs) delineated for the $2010 \mathrm{PHC}$. A total of 427 clusters were selected, 216 in urban areas and 211 in rural areas. The second stage involved the systematic sampling of households. A household listing operation was undertaken in all the selected EAs in January-March 2014, and households to be included in the survey were randomly selected from the list. About 30 households were selected from each cluster to constitute the total sample size of 12,831 households.

\section{Study Population and Sample Selection}

Dyads of mothers and children aged 6-23 months extracted from the women's questionaaire constituted the population for analysis. This study employed this group because it forms the basis of the WHO recommendation in calculating the IYCF indicators. The study sample (1640) was selected out of all (1740) children 6-23 months old. The sample selection is indicated in Figure below.

Figure 1: Study population and sample selection

\section{Acquisition of Data}


The data for the study was acquired online from the Measure DHS. A registration form was filled to register with Measure DHS. A brief proposal of the study indicating what the data set was going to be used for was sent to Measure DHS. Then, an approval was given to download the dataset.

\section{Description and definition of variables}

The study used minimum meal frequency as the dependent variable. This indicator for appropriate complementary feeding was created in accordance to the WHO guidelines [34]. Minimum meal frequency was defined as children 6-23 months of age who received solid, semi-solid or soft foods a minimum number of times in the previous day. The minimum required frequency varied by child age and breastfeeding status [22]. In the DHS set of questions, one of it was for the respondent to state the number of times the child received solid, semi-solid or soft food in the past day. Three questions assessed the feeding frequency of infant formula, milk and yoghurt. These frequencies were used to calculate the number of milk feeds which were all found in the women's questionnaire of the GDHS.

The independent variables for the study were: age of child, sex of child, age of mother, mother's educational attainment, residence, household wealth status, number of children less than five years, control over women's income, decision on large household purchases, mother's occupation, decision on family visits, decision on own health, attitude to violence, ownership of house and ownership of land.

Three dimensions of women's empowerment: (i) economic empowerment (control over women's income, decision making on large household purchases, work) (ii) socio-familial empowerment (decision making regarding family visits, women's own health, and attitude towards domestic violence under five scenarios) and (iii) legal empowerment (women's judicial and legislative entitlements over land and over house) are used in this study.

Age of child was recoded into 6-8 months, 9-11 months, 12-17 months and 18-23 months. Sex of the child was categorical (male/female). The number of children less than five years and mothers' age were captured as a continuous variable in the multivariate analysis. Control over women's income, large household purchases decision on family visits and own health was recoded as respondent alone, respondent and husband /partner, and husband / partner alone. Mother's occupation was recoded as "Not working", "Agricultural/labour" and "White collar". Attitude towards violence comprised a blend of questions on violence combined and the response variable was recoded as "Don't know", "No" and "Yes".

\section{Statistical Analysis}

Descriptive statistics were run to show the nature of independent variables. Multiple linear regression was applied to determine the association of the independent variables on the dependent variable. This was because our dependent variable (meal frequency) was continuous [35] [36]. Four models in total were estimated to demonstrate the associations between the various dimensions of women empowerment as well as socio-demographic factors and IYCF practices. Model 1 constituted the economic empowerment variables; control over women's income, decision on large household purchases and maternal occupation. 
In Model 2, socio-familial variables; decision on family visits, decision on own health and attitude to violence were added to model 1. Model 3 now included the legal empowerment variables of ownership of house and land to the Model 2. The last model now included the demographic characteristics comprising; the age of child, sex of child, age of mother, mother's educational attainment, residence, household wealth status and number of children less than five years. The data processing was accomplished using Stata version 13.0 software. The statistical significance level was set at $P<0.10, P<0.05$ and $P<0.01$.

\section{Results}

\section{Background Characteristics of Respondents}

More than half (52\%) of the infant and young children were males. The highest percentage (34\%) of the children was within the ages of 12-17 months. Mothers' ages showed low proportions for age groups $15-19(6 \%), 40-44(6 \%)$ and $45-49$ (2\%) years; mothers within the ages of $25-29$ years had the highest proportion (28\%). Most (55\%) of the respondents were residents in rural areas. Few (4.4\%) of them were better educated (post-secondary education) while about one-fourth $(26.55 \%)$ had no education. The highest (50.30\%) proportion of mothers had secondary education. The results also showed that the highest proportion (23\%) of the respondents were in the poorest category while those in the richest quintile had the lowest proportion (17.44\%) (Table 1). 
Table 1

Background characteristics of the respondents, categorical variables

\begin{tabular}{|c|c|c|}
\hline$n=1640$ & Freq. & Percent (\%) \\
\hline \multicolumn{3}{|l|}{ Sex of child } \\
\hline Male & 851 & 51.88 \\
\hline Female & 789 & 48.12 \\
\hline \multicolumn{3}{|l|}{ Age of mother } \\
\hline $15-19$ & 95 & 5.81 \\
\hline $20-24$ & 296 & 18.01 \\
\hline $25-29$ & 466 & 28.4 \\
\hline $30-34$ & 372 & 22.7 \\
\hline $35-39$ & 281 & 17.13 \\
\hline $40-44$ & 104 & 6.37 \\
\hline $45-49$ & 26 & 1.58 \\
\hline \multicolumn{3}{|l|}{ Place of residence } \\
\hline Urban & 739 & 45.09 \\
\hline Rural & 901 & 54.91 \\
\hline \multicolumn{3}{|l|}{ Educational level } \\
\hline No education & 435 & 26.55 \\
\hline Primary & 308 & 18.75 \\
\hline Secondary & 825 & 50.3 \\
\hline Higher & 72 & 4.4 \\
\hline \multicolumn{3}{|l|}{ Age of child } \\
\hline 6 to 8 & 309 & 18.87 \\
\hline 9 to 11 & 270 & 16.46 \\
\hline 12 to 17 & 563 & 34.35 \\
\hline 18 to 23 & 498 & 30.32 \\
\hline \multicolumn{3}{|l|}{ Wealth } \\
\hline Poorest & 365 & 22.26 \\
\hline
\end{tabular}




\begin{tabular}{|c|c|c|c|}
\hline Variable & $n=1640$ & Freq. & Percent (\%) \\
\hline Poorer & & 353 & 21.55 \\
\hline Middle & & 303 & 18.45 \\
\hline Richer & & 333 & 20.3 \\
\hline Richest & & 286 & 17.44 \\
\hline \multicolumn{4}{|c|}{ Source; Computed for GDHS 2014} \\
\hline
\end{tabular}

\section{Association Between Women Empowerment And Minimum Meal Frequency}

The findings show that women empowerment had significant association with minimum meal frequency. Children of mothers who made decisions with their partners concerning large household purchases were reported to have increased minimum meal frequency compared to those who had their partners/others make decisions $(\beta=0.351, p<0.01)$. With respect to decisions on family visits, a positive association was found with meeting minimum meal frequency for children of mothers who made decisions on visits alone compared with those whose decisions were made by partners or other persons aside themselves ( $\beta=$ $0.743, p<0.01)$.

The results further shows positive significant association with attaining minimum meal frequency and women's disapproval of violence against women $(\beta=1.171, p<0.10)$. Unexpectedly, mothers who jointly owned houses with their partners had their children unlikely to attain minimum meal frequency as compared to mothers who did not own houses $(\beta=-0.245, p<0.10)$. Land ownership showed varying levels of significance. For instance, a woman's joint ownership of land had significant positive association with attainment of minimum meal frequency for children than their counterparts who did not own lands $(\beta=0.470, p<0.01)$. (Table 2$)$

Again, increasing child's age (18-23 months) was positively associated $(\beta=1.387, p<0.01)$ with meeting the required meal frequency. The results also show a positive association between educational attainment of mothers and the minimum meal frequency of their children. Mothers with higher education $(\beta=0.496, p<0.10)$ reported increased meal frequency for their children. A negative significant relationship with minimum meal frequency was found for women with primary education $(\beta=-0.325, p<$ $0.10)$. Rural residence $(\beta=-0.298, p<0.10)$ was negatively associated with attaining minimum meal frequency among children (Table 2). 
Table 2

Regression analysis of women empowerment and demographics on minimum meal frequency Independent variables Model 1

Model 2 Model 3

Model 4

\section{Economic factors}

Control over women's

income

\begin{tabular}{lllll} 
Respondent alone & -0.0528 & -0.0953 & -0.152 & -0.068 \\
\hline $\begin{array}{l}\text { Respondent and } \\
\text { husband/partner }\end{array}$ & {$[-0.618,0.513]$} & {$[-0.670,0.479]$} & {$[-0.727,0.423]$} & {$[-0.595,0.459]$} \\
& -0.0819 & -0.029 & -0.119 & -0.1 \\
\hline $\begin{array}{l}\text { Husband/Partner or other } \\
\text { alone }\end{array}$ & Ref & Ref & Ref & Ref
\end{tabular}

Decision on large household purchases

\begin{tabular}{lllll} 
Respondent alone & 0.251 & 0.118 & 0.0807 & -0.186 \\
\hline $\begin{array}{l}\text { Respondent and } \\
\text { husband/partner }\end{array}$ & 0.118 & $0.273^{\star}$ & $0.275^{\star}$ & $0.351^{\star * *}$ \\
\hline & {$[-0.123,0.360]$} & {$[-0.00830,0.554]$} & {$[-0.00675,0.556]$} & {$[0.0851,0.617]$}
\end{tabular}

Husband/Partner or other Ref

Ref

Ref

Ref

alone

Mothers occupation

\begin{tabular}{lllll} 
Not working & Ref & Ref & Ref & Ref \\
\hline White collar & 0.0859 & 0.128 & 0.132 & 0.0543 \\
\hline $\begin{array}{l}\text { Agricultural/labour } \\
\begin{array}{l}\text { Socio-familial } \\
\text { empowerment }\end{array}\end{array}$ & Ref & Ref & Ref & Ref \\
\hline
\end{tabular}

Family visit decision

\begin{tabular}{llll} 
Respondent alone & $0.514^{\star \star}$ & $0.551^{\star \star}$ & $0.743^{\star \star \star}$ \\
\hline $\begin{array}{l}\text { Respondent and } \\
\text { husband/partner }\end{array}$ & {$[0.0792,0.949]$} & {$[0.116,0.986]$} & {$[0.329,1.157]$} \\
\hline
\end{tabular}




\section{Independent variables}

Husband/Partner or other alone

Own health

Respondent alone

Respondent and husband/partner

Husband/Partner or other
alone
Attitude towards violence

Don't know

No

Model 1

$-0.059$

$-0.0424$

$-0.0127$

$[-0.418,0.300]$

$[-0.402,0.318]$

$[-0.343,0.318]$

$-0.141$

$-0.16$

$-0.238$

$[-0.505,0.222]$

$[-0.527,0.207]$

$[-0.585,0.109]$

Ref

Ref

Ref

Ref

Ref

Ref

$1.169 *$

0.866

0.243

[-0.114,2.451]

[-0.422,2.155]

$[-0.978,1.464]$

$1.458 * *$

$1.171^{\star}$

0.467

\section{Yes \\ Legal Empowerment}

House

Does not own

$[0.156,2.761]$

$[-0.135,2.477]$

$[-0.785,1.719]$

Alone only Ref

Ref

Jointly only

Both alone and jointly

$0.135 \quad 0.118$

$[-0.385,0.654]$

$[-0.375,0.611]$

$-0.345^{\star \star}$

$-0.245^{\star}$

[-0.664,-0.0265]

[-0.535,0.0440]

$-0.198$

$-0.357$

[-0.885,0.489]

$[-0.984,0.269]$

Land

Does not own

Ref

Ref

Alone only

$-0.129$

$-0.358^{*}$ 


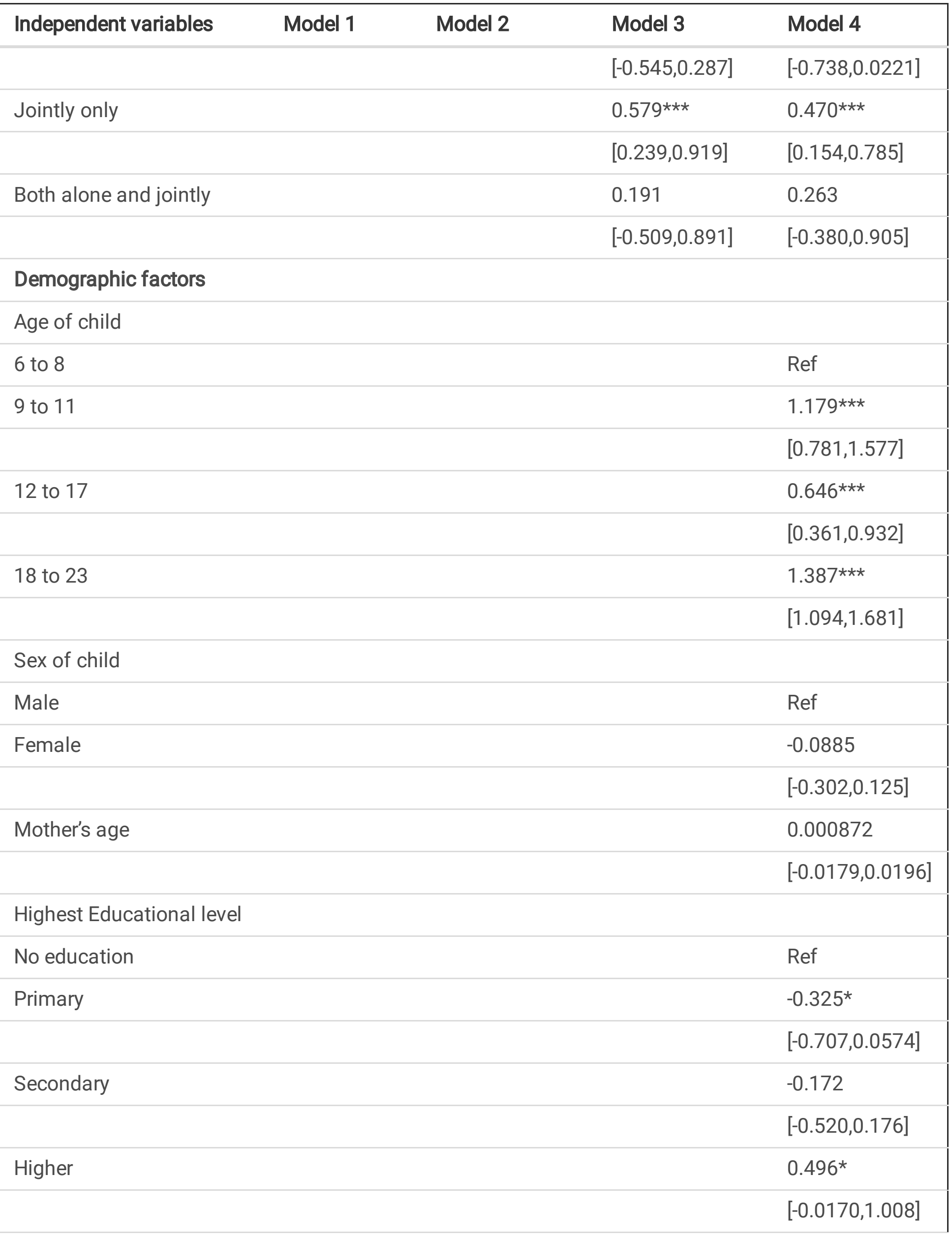




\begin{tabular}{|c|c|c|c|c|}
\hline Independent variables & Model 1 & Model 2 & Model 3 & Model 4 \\
\hline \multicolumn{5}{|l|}{ Residence } \\
\hline Urban & & & & Ref \\
\hline \multirow[t]{2}{*}{ Rural } & & & & $-0.298^{*}$ \\
\hline & & & & {$[-0.600,0.00450]$} \\
\hline \multicolumn{5}{|l|}{ Household wealth } \\
\hline Poorest & & & & Ref \\
\hline \multirow[t]{2}{*}{ Poorer } & & & & -0.0412 \\
\hline & & & & {$[-0.429,0.346]$} \\
\hline \multirow[t]{2}{*}{ Middle } & & & & -0.163 \\
\hline & & & & {$[-0.599,0.274]$} \\
\hline \multirow[t]{2}{*}{ Richer } & & & & -0.0345 \\
\hline & & & & {$[-0.513,0.444]$} \\
\hline \multirow[t]{2}{*}{ Richest } & & & & -0.238 \\
\hline & & & & {$[-0.808,0.332]$} \\
\hline \multirow{2}{*}{$\begin{array}{l}\text { Number of children less } \\
\text { than 5yrs }\end{array}$} & & & & -0.0163 \\
\hline & & & & {$[-0.159,0.127]$} \\
\hline \multirow[t]{2}{*}{ _cons } & 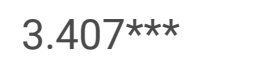 & $1.942^{\star \star \star}$ & $2.306 * \star \star$ & $2.465^{\star \star \star}$ \\
\hline & {$[2.834,3.980]$} & {$[0.516,3.369]$} & {$[0.866,3.747]$} & {$[0.812,4.118]$} \\
\hline R-sq & 0.006 & 0.041 & 0.073 & 0.289 \\
\hline adj. $R^{2}$ & -0.004 & 0.016 & 0.034 & 0.231 \\
\hline \multicolumn{5}{|c|}{$95 \%$ confidence intervals in brackets } \\
\hline \multicolumn{5}{|l|}{$\begin{array}{l}{ }^{*} p<0.10,{ }^{* *} p<0.05,{ }^{* * *} p< \\
0.01\end{array}$} \\
\hline Source: Computed from & S 2014 & & & \\
\hline
\end{tabular}

\section{Discussion}

Understanding the drivers of mother's ability to meet the minimum meal frequency among children less than two years is important for child survival and later life outcomes including education and earnings 
[37] [38] [39]. Anchored in empowerment thinking, this study aimed to understand the association between three indicators of women's empowerment and minimum meal frequency among Ghanaian children aged 6-23 months. Data was pooled from the 2014 Ghana Demographic and Health Survey. The key findings are mother's decision on family visits and decision on large household purchases had positive associations with meal frequency while, ownership of house had a negative association with meal frequency.

The first issue is that the decision on family visits had a significant association with the measure of minimum meal frequency. The argument is that as women gain more freedom to visit other families in the community, they tend to have wider social networks with other community members and exchange ideas and cultural beliefs on child-care practices [22]. Likewise, WHO (2020) [40] argues that mothers and families need support from community and mother support groups for their children to be fed optimally. Thus, the influence of social environment, close relatives and friends helps mothers to achieve the goal of providing appropriate meals for children [41] [42].

Decision-making control on large household purchases had significant positive association with minimum meal frequency. This finding is similar to studies in Philippines [43] and India [44], where maternal contribution to household income and power over household earnings and decision making were significantly associated with minimum meal frequency practices. This may be attributed to the fact that when women are involved in household purchases in large quantities, there is the likelihood to purchase food items. This further suggests that in order to meet the required number of meals a day for children, households need to purchase sufficient food stock [45] [46] [47].

Ownership of house decreased the ability of meeting IYCF practices for minimum meal frequency. In a study in Benin, it was not quite clear why women's entitlement to land and houses decreased their ability to feed children appropriately compared with similar women with no land or home ownership. This may be because asset inheritance rules can be complicated and also varies across settings [48]. However, in the context of India, Rao argued that granting land rights to women led to an increase of work burden without much improvement in their food security or social status [49].

Younger child age consistently showed no significance with meeting the criteria of minimum meal frequency. This finding is in line with previous studies in which younger children had higher odds of being fed inadequately in terms of frequency in Bangladesh [50]. Wondu et al., (2017)[51] also posit early child age bracket as risk group for inadequate minimum meal frequency. It has been noticed from the study that in the Ghanaian context, children are likely to meet this IYCF practice as they age which could be due to the fact that Ghanaian women practice IYCF better as the child survives. Similar results have also been noticed in Ethiopia [52] [39], Ghana[53] and Sri Lanka [54]. Evidence also suggest that children are introduced to more complementary meals as they grow and their teeth develops and hence, the frequency of meals is increased although there is a downside of loss of appetite which may lead to reduction in meal frequency [55] [56] [39]. 
Additionally, mother's educational level had positive association with minimum meal frequency. Having high maternal education and interactions with family members and friends have been posited to enhance child nutrition [57] [58]. This validates previous work of Demilew et al., (2017)[59] which postulated that educated mothers might read books, leaflets and magazines, and might have a better chance of exposure to nutrition education about IYCF through mass media than their counterparts. Previous evidence in Nepal has it that mother's education is vital for determining the feeding practices [60]. The probable reasoning could be that educated mothers are well informed and are more adherent to required feeding practices.

Rural settlement of respondents had a significant negative effect to meeting minimum meal frequency. This is inconsistent with an earlier finding which indicated that mothers who lived in urban areas were likely to attain the recommended minimum meal frequency [61]. They explain that urban mothers are aware and have more access to media which promotes complementary feeding practices. Although time restrictions, workload and other effects of modernization may affect mothers living at urban areas, mothers living in rural areas may not have enough education on complementary feeding practices altogether.

\section{Strengths And Limitations}

Limitation comes with self-reporting made by the mother. The GDHS data has a limitation of having only one day of diet recall per child, which may not be representative of the day-to-day dietary intake. Only one data point was used in the study because there have been changes in the definition of IYCF practices indicators by the World Health Organisation (WHO) and so comparison of indicators with previous years will be problematic. There is no loss to follow-up because participants are interviewed once. However, only associations and not causality can be inferred due to the cross-sectional nature of the data.

\section{Conclusion And Recommendations}

The paper concludes that minimum meal frequency is influenced by various dimensions of empowerment of women such as economic and socio-familial empowerment. Specifically, joint decision on large household purchases, decision on family visits, ownership of land, age of child and mothers educational level improved minimum meal frequency. There is the need for improved advocacy for women to be involved in decision on family visits and large household purchases as it promotes frequent meal attainment of children. Additionally, mothers residing in rural areas impacted negatively on minimum meal frequency. Interventional programs by Ministry of Gender and Social protection, Ministry of Health as well as Ghana Health Service other stakeholders should target households and mothers with lower socio-demographics characteristics such as lower educational level to improve feeding at least the minimum frequency of children. Future studies could consider the influence of family members and husbands of mothers on minimum meal frequency. 


\section{Declarations}

\section{Ethics approval and consent to participant}

Not applicable

\section{Consent for publication}

Not applicable

\section{Availability of data and materials}

The dataset used in the study is freely available upon request from https://www.dhsprogram.com/data/dataset/Ghana_Standard-DHS_2014.cfm?flag=0

\section{Competing interest}

The authors declare that they have no competing interests

\section{Funding}

No funding

\section{Authors' contributions}

Louis Kobina Dadzie conceptualized and drafted the manuscript. Louis Kobina Dadzie conducted the data analysis for the study. Louis Kobina Dadzie, Joshua Amo-Adjei and Kobina Esia-Donkoh designed and critically reviewed the document. All authors read and approved the final version submitted.

\section{Acknowledgements}

Not applicable

\section{References}

[1] Neelon SE, Briley ME. Position of the American Dietetic Association: benchmarks for nutrition in child care. Journal of the American Dietetic Association. 2011 Apr 1;111(4):607-15.

[2] World Health Organisation. 2018. Global nutrition report. http://www.who. int/nutrition/globalnutritionreport/en/ accessed on 14/08/2020

[3] Prudhon C, Benelli P, Maclaine A, Harrigan P, Frize J. Informing infant and young child feeding programming in humanitarian emergencies: An evidence map of reviews including low and middle income countries. Maternal \& child nutrition. 2018 Jan;14(1):e12457. 
[4] Marriott BP, White A, Hadden L, Davies JC, Wallingford JC. World Health Organization (WHO) infant and young child feeding indicators: associations with growth measures in 14 low-income countries. Maternal \& child nutrition. 2012 Jul;8(3):354-70.

[5] Sinhababu A, Mukhopadhyay DK, Panja TK, Saren AB, Mandal NK, Biswas AB. Infant-and young childfeeding practices in Bankura district, West Bengal, India. Journal of health, population, and nutrition. 2010 Jun;28(3):294.

[6] UNICEF. Division of Communication. Tracking progress on child and maternal nutrition: a survival and development priority. Unicef; 2009.

[7] World Health Organisation. Global nutrition report. 2018 http://www.who. int/nutrition/globalnutritionreport/en/ Accessed on 13/08/2020

[8] United Nations Development Programme. "Background Guide,: Executive board of the United Nations Development Programme (UNDP). 2010 https://en.wikipedia.org/wiki/United_Nations_Development_Programme. Accessed on 12/08/2020 [9] United Nations Children's Fund. From the first hour of life. Making the case for improved infant and young child feeding everywhere. New York: United Nations Children's Fund. 2016 file:///Users/mac/Downloads/From-the-first-hour-of-life-1.pdf Accessed on 12/08/2020

[10] Khan GN, Ariff S, Khan U, Habib A, Umer M, Suhag Z, Hussain I, Bhatti Z, Ullah A, Turab A, Khan AA. Determinants of infant and young child feeding practices by mothers in two rural districts of Sindh, Pakistan: a cross-sectional survey. International breastfeeding journal. 2017 Dec 1;12(1):40.

[11] Gebremedhin S. Core and optional infant and young child feeding indicators in Sub-Saharan Africa: a cross-sectional study. BMJ open. 2019 Feb 1;9(2):e023238.

[12] World Health Organization. The double burden of malnutrition: policy brief. 2016 https://www.who.int/nutrition/publications/doubleburdenmalnutrition-policybrief/en/ Accessed on $12 / 07 / 2020$

[13] Nassanga P, Okello-Uma I, Ongeng D. The status of nutritional knowledge, attitude and practices associated with complementary feeding in a post-conflict development phase setting: The case of Acholi sub-region of Uganda. Food science \& nutrition. 2018 Nov;6(8):2374-85.

[14] Donkor CM, Lee J, Lelijveld N, Adams M, Baltussen MM, Nyante GG, Kerac M, Polack S, Zuurmond M. Improving nutritional status of children with Cerebral palsy: a qualitative study of caregiver experiences and community-based training in Ghana. Food Science \& Nutrition. 2019 Jan;7(1):35-43.

[15] Abang CO. Association between breastfeeding and complementary feeding practices and infant growth in the Builsa District (Doctoral dissertation, University of Ghana). 
[16] Tampah-Naah AM, Kumi-Kyereme A, Amo-Adjei J. Maternal challenges of exclusive breastfeeding and complementary feeding in Ghana. PloS one. 2019 May 2;14(5):e0215285

[17] Mulenga E, Amukugo HJ, Shilunga AP. The experiences of mothers and caregivers on feeding practices of children under the age of five years with undernutrition in Oshikoto region, Namibia. 2018

[18] United Nations Development Programme. (2010). "Background Guide,: Executive board of the United Nations Development Programme (UNDP) Retrieved from

https://en.wikipedia.org/wiki/United_Nations_Development_Programme.

[19] Adjei SB. Assessing women empowerment in Africa: A critical review of the challenges of the gender empowerment measure of the UNDP. Psychology and Developing Societies. 2015 Mar;27(1):58-80.

[20] United States Agency for International Development. (2012). "Policy Framework for Bilateral Foreign Aid". 2012 https://www.usaid.gov/sites/default/files/documents/1868/201mam.pdf Accessed on $10 / 10 / 2020$

[21] Ewerling F, Lynch JW, Victora CG, van Eerdewijk A, Tyszler M, Barros AJ. The SWPER index for women's empowerment in Africa: development and validation of an index based on survey data. The Lancet Global Health. 2017 Sep 1;5(9):e916-23.

[22] Na M, Jennings L, Talegawkar SA, Ahmed S. Association between women's empowerment and infant and child feeding practices in sub-Saharan Africa: an analysis of Demographic and Health Surveys. Public health nutrition. 2015 Dec;18(17):3155-65.

[23] Ickes SB, Hurst TE, Flax VL. Maternal literacy, facility birth, and education are positively associated with better infant and young child feeding practices and nutritional status among Ugandan children. The Journal of nutrition. 2015 Nov 1;145(11):2578-86.

[24] Imdad A, Yakoob MY, Bhutta ZA. Impact of maternal education about complementary feeding and provision of complementary foods on child growth in developing countries. BMC public health. 2011 Dec 1;11(S3):S25.

[25] Krasevec J, An X, Kumapley R, Bégin F, Frongillo EA. Diet quality and risk of stunting among infants and young children in low-and middle-income countries. Maternal \& child nutrition. 2017 Oct;13:e12430.

[26] Darapheak C, Takano T, Kizuki M, Nakamura K, Seino K. Consumption of animal source foods and dietary diversity reduce stunting in children in Cambodia. International archives of medicine. 2013 Dec 1;6(1):29.

[27] Amugsi DA, Lartey A, Kimani-Murage E, Mberu BU. Women's participation in household decisionmaking and higher dietary diversity: findings from nationally representative data from Ghana. Journal of Health, Population and Nutrition. 2016 Dec 1;35(1):16. 
[28] Amugsi DA, Mittelmark MB, Oduro A. Association between maternal and child dietary diversity: an analysis of the Ghana demographic and health survey. PloS one. 2015 Aug 25;10(8):e0136748.

[29] Ruel MT, Alderman H, Maternal and Child Nutrition Study Group. Nutrition-sensitive interventions and programmes: how can they help to accelerate progress in improving maternal and child nutrition?. The lancet. 2013 Aug 10;382(9891):536-51.

[30] Ganle JK, Afriyie K, Segbefia AY. Microcredit: Empowerment and disempowerment of rural women in Ghana. World Development. 2015 Feb 1;66:335-45.

[31] Jinia NJ. Microcredit and Women's Empowerment. Does Microcredit Promote the Borrowers to Participate in the Household Decision-making Process in Bangladesh?.

[32] Solomon BB. Black empowerment: Social work in oppressed communities.

[33] Ghana Statistical Service; Ghana Health Service and ICF Macro; (2015). Ghana Demographic and Health Survey 2014: Key indicators. Accra: GSS, GHS and ICF Macro.

[34] World Health Organization.2010

[35] Hoffmann JP. Regression models for categorical, count, and related variables: An applied approach. Univ of California Press; 2016 Aug 16.

[36] Tanni SE, Patino CM, Ferreira JC. Correlation vs. regression in association studies. Jornal Brasileiro de Pneumologia. 2020;46(1).

[37] UNICEF. Infant and young child feeding, nutrition section program. June 2011. New York.

[38] Frempong RB, Annim SK. Dietary diversity and child malnutrition in Ghana. Heliyon. 2017 May 1;3(5):e00298.

[39] Tegegne M, Sileshi S, Benti T, Teshome M, Woldie H. Factors associated with minimal meal frequency and dietary diversity practices among infants and young children in the predominantly agrarian society of Bale zone, Southeast Ethiopia: a community based cross sectional study. Archives of Public Health. 2017 Dec 1;75(1):53.

[40] World Health Organization (2020) Infant and young child feeding. Retrieved from https://www.who.int/news-room/fact-sheets/detail/infant-and-young-child-feeding

[41] Li G, Cong J, Li L, Li Y. Effects of nursing with information support and behavior intervention on lactation and breastfeeding success rate for primiparas. Int. J. Clin. Exp. Med. 2018 Jan 1;11:2617-23.

[42] Santacruz-Salas E, Aranda-Reneo I, Segura-Fragoso A, Cobo-Cuenca Al, Laredo-Aguilera JA, CarmonaTorres JM. Mothers' Expectations and Factors Influencing Exclusive Breastfeeding during the First 6 Months. International Journal of Environmental Research and Public Health. 2020 Jan;17(1):77. 
[43] Schmeer KK. Married women's resource position and household food expenditures in Cebu, Philippines. Journal of Marriage and Family. 2005 May;67(2):399-409.

[44] Dhami MV, Ogbo FA, Osuagwu UL, Agho KE. Prevalence and factors associated with complementary feeding practices among children aged 6-23 months in India: a regional analysis. BMC public health. 2019 Dec 1;19(1):1034.

[45] Aguayo VM. Complementary feeding practices for infants and young children in South Asia. A review of evidence for action post-2015. Maternal \& Child Nutrition. 2017 Oct;13:e12439.

[46] Torlesse H, Raju D. Feeding of Infants and Young Children in South Asia. Policy Research Working Paper, World Bank Group 2019.

[47] Wagris M, Seid A, Kahssay M, Ahmed O. Minimum Meal Frequency Practice and Its Associated Factors among Children Aged 6-23 Months in Amibara District, North East Ethiopia. Journal of Environmental and Public Health. 2019 Dec 18;2019.

[48] Kabeer N. Resources, agency, achievements: Reflections on the measurement of women's empowerment. Development and change. 1999 Jul;30(3):435-64.

[49] Rao N. Land rights, gender equality and household food security: Exploring the conceptual links in the case of India. Food Policy. 2006 Apr 1;31(2):180-93.

[50] Kabir I, Khanam M, Agho KE, Mihrshahi S, Dibley MJ, Roy SK. Determinants of inappropriate complementary feeding practices in infant and young children in Bangladesh: secondary data analysis of Demographic Health Survey 2007. Maternal \& child nutrition. 2012 Jan;8:11-27.

[51] Wondu Garoma B, Yang N. Determinants of suboptimal complementary feeding practices among children aged 6-23 months in selected urban slums of Oromia zones (Ethiopia). J Nutr Food Sci. 2017;7(593):2-13.

[52] Beyene M, Worku AG, Wassie MM. Dietary diversity, meal frequency and associated factors among infant and young children in Northwest Ethiopia: a cross-sectional study. BMC public health. 2015 Dec 1;15(1):1007.

[53] Saaka M, Larbi A, Mutaru S, Hoeschle-Zeledon I. Magnitude and factors associated with appropriate complementary feeding among children 6-23 months in northern Ghana. BMC Nutrition. 2016 Dec 1;2(1):2.

[54] Senarath U, Godakandage SS, Jayawickrama H, Siriwardena I, Dibley MJ. Determinants of inappropriate complementary feeding practices in young children in Sri Lanka: secondary data analysis of demographic and health survey 2006-2007. Maternal \& child nutrition. 2012 Jan;8:60-77. 
[55] Khanal V, Sauer K, Zhao Y. Determinants of complementary feeding practices among Nepalese children aged 6-23 months: findings from demographic and health survey 2011. BMC pediatrics. 2013 Dec 1;13(1):131.

[56] Aemro M, Mesele M, Birhanu Z, Atenafu A. Dietary diversity and meal frequency practices among infant and young children aged 6-23 months in Ethiopia: a secondary analysis of Ethiopian demographic and health survey 2011. Journal of nutrition and metabolism. 2013 Nov 24;2013.

[57] Shroff M, Griffiths P, Adair L, Suchindran C, Bentley M. Maternal autonomy is inversely related to child stunting in Andhra Pradesh, India. Maternal \& Child Nutrition. 2009 Jan;5(1):64-74.

[58] Prakash R, Singh A, Pathak PK, Parasuraman S. Early marriage, poor reproductive health status of mother and child well-being in India. BMJ Sexual \& Reproductive Health. 2011 Jul 1;37(3):136-45.

[59] Demilew YM, Tafere TE, Abitew DB. Infant and young child feeding practice among mothers with 024 months old children in Slum areas of Bahir Dar City, Ethiopia. International breastfeeding journal. 2017 Dec 1;12(1):26.

[60] Gautam KP, Adhikari M, Khatri RB, Devkota MD. Determinants of infant and young child feeding practices in Rupandehi, Nepal. BMC research notes. 2016 Dec 1;9(1):135.

[61] Belew AK, Ali BM, Abebe Z, Dachew BA. Dietary diversity and meal frequency among infant and young children: a community based study. Italian journal of pediatrics. 2017 Dec 1;43(1):73.

\section{Figures}

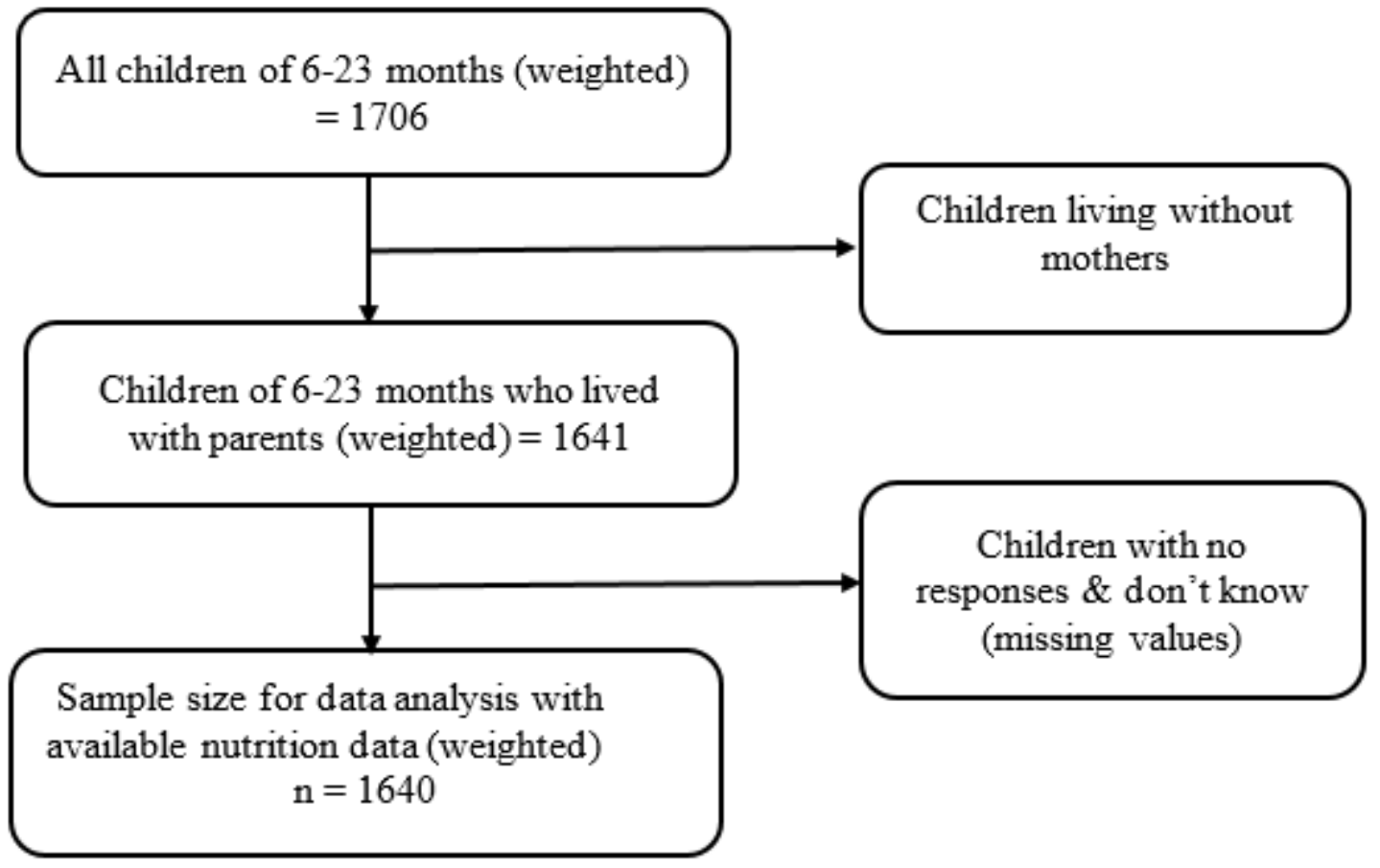


Figure 1

Study population and sample selection 